\title{
Association of antioxidant vitamins and oxidative stress levels in pregnancy with infant growth during the first year of life
}

\author{
Juhee Hong ${ }^{1}$, Eun Ae Park ${ }^{2}$, Young-Ju Kim ${ }^{3}$, Hwa Young Lee ${ }^{4}$, Bo-Hyun Park' \\ Eun-Hee $\mathrm{Ha}^{1}$, Kyoung Ae Kong ${ }^{1}$ and Hyesook Park ${ }^{1, *}$ \\ 'Department of Preventive Medicine, College of Medicine, Ewha Womans University, 911 -1 Mok-dong, \\ Yangcheon-Gu, Seoul 158-710, South Korea: ${ }^{2}$ Department of Pediatrics, Ewha Womans University, Seoul, South \\ Korea: ${ }^{3}$ Department of Obstetrics and Gynecology, Ewha Womans University, Seoul, South Korea: ${ }^{4}$ Department \\ of Anatomy, School of Medicine, Medical Research Center, Ewha Womans University, Seoul, South Korea
}

Submitted 1 March 2007: Accepted 9 September 2007: First published online 7 December 2007

\begin{abstract}
Objective: Whereas there are numerous reports in the literature relating the impact of maternal nutritional status on subsequent birth outcome, much less is known about the long-term impact on infant growth after birth. Therefore, we conducted a prospective cohort study to investigate the association of maternal micronutrient status (vitamins A, C and E, folate) and oxidative stress status in pregnancy with infant growth during the first year of life.

Design: Prospective cohort study.

Setting: Outpatient clinic of obstetrics, Ewha Womans University Hospital, Seoul, South Korea.

Subjects and methods: Two groups were constructed for this study - the Ewha pregnancy cohort $(n=677)$ and the infant growth cohort comprising follow-up live newborns of all the recruited pregnant women $(n=317)$. Maternal serum vitamin and urinary oxidative stress levels were collected and infant weights and heights were measured at birth and at 6 and 12 months after birth.

Results: Division of the subjects into folate-deficient and normal groups revealed that infant weight and height at 0, 6 and 12 months were adversely affected by folate deficiency. High maternal vitamin $\mathrm{C}$ was associated with increased infant weight and height at birth and after birth.

Conclusion: Our findings indicate the importance of preventing folate deficiency and supplementing vitamin $\mathrm{C}$ during pregnancy.
\end{abstract}

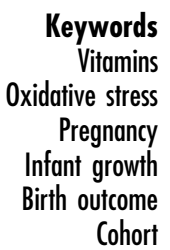

Cohort
Maternal nutrition in pregnancy can have a profound and sustained impact on the health, development and wellbeing of the foetus, newborn and infant, as well as on the pregnant woman herself. The foetus is totally dependent on the mother for the supply of nutrients essential to maintain its life. An optimal maternal nutritional status has been shown to reduce the risks of a preterm birth and low birth weight ${ }^{(1-3)}$, improve postnatal growth ${ }^{(4,5)}$, and reduce both maternal and infant morbidity and mortality ${ }^{(6-9)}$. Despite a trend of improved infant growth in most countries due to enhanced intakes of macronutrients ${ }^{(10)}$, a low maternal nutritional status during the critical stage of foetal development subsequently contributes to growth retardation in the offspring and adverse health outcomes in later life ${ }^{(11)}$. In particular, macronutrients and associated foetal growth have been widely emphasised, but deficiencies in maternal micronutrients and induced oxidative stress have not received much attention. Therefore, adverse foetal environments caused by maternal micronutrient deficiency or a high level of oxidative stress need to be investigated from a public health perspective, with identification of their pivotal role in infant growth.

Many observational studies, as well as clinical trials, have aimed at determining the association of maternal vitamin or mineral status with birth outcomes ${ }^{(12-18)}$. Vitamins A, C and $\mathrm{E}$ are essential in a wide range of physiological processes such as pregnancy, promotion of general growth, ameliorating increased oxidative stress during pregnancy, and the provision of antioxidant defence to the foetus ${ }^{(19,20)}$. Downie et al. found that maternal vitamin A supplementation resulted in increased foetal growth ${ }^{(21)}$. However, two large randomised trials in Nepal and Indonesia found that vitamin A had no effect on foetal growth or loss ${ }^{(22,23)}$. Several observational studies found associations between low vitamin $\mathrm{C}$ status and low birth weight ${ }^{(24-26)}$, and another study found that improved maternal vitamin $\mathrm{E}$ and $\mathrm{C}$ status was associated with increased birth size ${ }^{(27)}$. Folate plays a significant role 
as a coenzyme in the synthesis of DNA, RNA and certain amino acids, and in formulating normal foetal development ${ }^{(28,29)}$. However, there is a large body of literature reporting inconsistent effects of folate on pregnancy: some studies have shown its beneficial effects on improving birth weight and decreasing preterm delivery $^{(26,30,31)}$, but others have found no such associations ${ }^{(32)}$. Maternal oxidative stress due to environmental factors such as smoke, air pollution and chemicals has been shown to counteract the actions of the abovementioned antioxidant vitamins in protecting the foetus from damage caused by oxygen free radicals ${ }^{(33,34)}$.

While there is considerable literature relating the impact of maternal nutritional status such as vitamins and minerals on subsequent birth outcomes such as birth weight and foetal development and growth, much less is known about the long-term impacts on infant growth after birth. According to the concept of foetal programming, adverse foetal environments might have a negative effect on postnatal development, and several studies have investigated the association between postnatal growth and maternal micronutrient status. However, these studies either found no association or were not conducted on a general population. For example, a randomised controlled trial on the effects of vitamin A on weight and height in children involved only anaemic children with low socio-economic status ${ }^{(35)}$. Another randomised double-blind trial found no association between vitamin A and infant growth at 1 year after birth ${ }^{(36)}$. Accordingly, further studies are needed to clarify the real situation. Therefore, the current study investigated the association of maternal micronutrient status (vitamins A, C and E, folate) and oxidative stress in pregnancy with infant growth during the first year of life.

\section{Methods}

\section{Ewha pregnancy cobort}

Two groups were constructed for this study: the Ewha pregnancy cohort and the infant growth cohort comprising follow-up live newborns of all the recruited pregnant women (Fig. 1). From August 2001 to September 2005, the Ewha pregnancy cohort was constructed from 835 healthy pregnant women who visited Ewha Womans University Hospital for prenatal care during gestational weeks 24-28 and agreed to participate in the study. Women in this population with twin births $(n=28)$ or with pregnancyinduced hypertension or gestational diabetes $(n=130)$ were excluded, and hence 677 subjects were examined. Anthropometric data, sociodemographic and behavioural information, and disease status were collected by trained nurses during visits by the women to the outpatient clinic of the university hospital. Gestational age of the neonate at delivery was assessed by the date of the last menstrual period and by ultrasound measurement.

\section{Infant growtb cobort}

The infant group was constructed from infants who were born to mothers in the pregnancy cohort, and they were followed up during the first year of life. Among 811 infants born, 317 infants with follow-up data from birth to 1 year were analysed. Trained nurses working in delivery rooms collected information on birth outcomes based on medical records.

\section{Maternal serum and urinary measurements}

In order to obtain serum micronutrient status (folate, vitamins $\mathrm{A}, \mathrm{C}$ and $\mathrm{E}$ ), fasting venous blood was drawn from the subjects between 24 and 28 weeks of gestation. Serum was separated by centrifugation within $4 \mathrm{~h}$ and stored at $-70^{\circ} \mathrm{C}$ until analysis. The amount of serum folate was measured by a radioimmunoassay kit (Diagnostic Products Corporation). Plasma levels of vitamin A (retinol), vitamin C (L-ascorbic acid) and vitamin $\mathrm{E}$ ( $\alpha$-tocopherol) were measured using high-performance liquid chromatography (HPLC) on a Shimadzu SCL-10A system, under the conditions listed in Table $1^{(37,38)}$. $\alpha$-Tocopherol and retinol were measured by Bieri's method. Two hundred microlitres of plasma was combined with $1.0 \mathrm{ml}$ of hexane, vortexed, and then centrifuged for $10 \mathrm{~min}$ at $2000 \mathrm{~g}$. The hexane was removed, the organic solvent layer was evaporated to dryness under nitrogen and reconstituted with $100 \mu \mathrm{l}$ of mobile phase solution, and then $10 \mu \mathrm{l}$ of the reconstituted solution was subjected to HPLC analysis using tocopherol acetate $(50 \mu \mathrm{g} / \mathrm{ml})$ as an internal standard. For vitamin $\mathrm{C}$ analysis, $100 \mu \mathrm{l}$ of the plasma was mixed with $100 \mu \mathrm{l}$ of $5 \%$ metaphosphoric acid, vortexed, and then centrifuged for $10 \mathrm{~min}$ at $3000 \mathrm{~g}$. The supernatant was filtered by a $0 \cdot 45-\mu \mathrm{m}$ syringe filter, and $10 \mu \mathrm{l}$ of the sample was subjected to HPLC analysis.

During the same period, oxidative stress status was assessed by measuring the spontaneous urinary concentrations of malondialdehyde (MDA) and 8-hydroxydeoxyguanosine (8-OHdG). MDA was measured by HPLC on adduct obtained with thiobarbituric acid, and 8-OHdG was measured by competitive in vitro enzyme-linked immunosorbent assay for the quantitative measurement of oxidative DNA adducts.

\section{Postnatal growth measurement}

To assess the growth of infants during the first year of life, their weight and height were measured three times: at birth, and 6 and 12 months after birth. Birth weights and heights were routinely measured by trained nurses in the delivery room, and weights and heights after birth were measured during visits by the subjects to an outpatient clinic. In cases where measurement at the clinic was not possible, a questionnaire asking for information on weight, height and general development of the infant was mailed. The agreements of measured weight and height between the outpatient visit and mail were assessed using Spearman correlation analysis. The resulting very high 


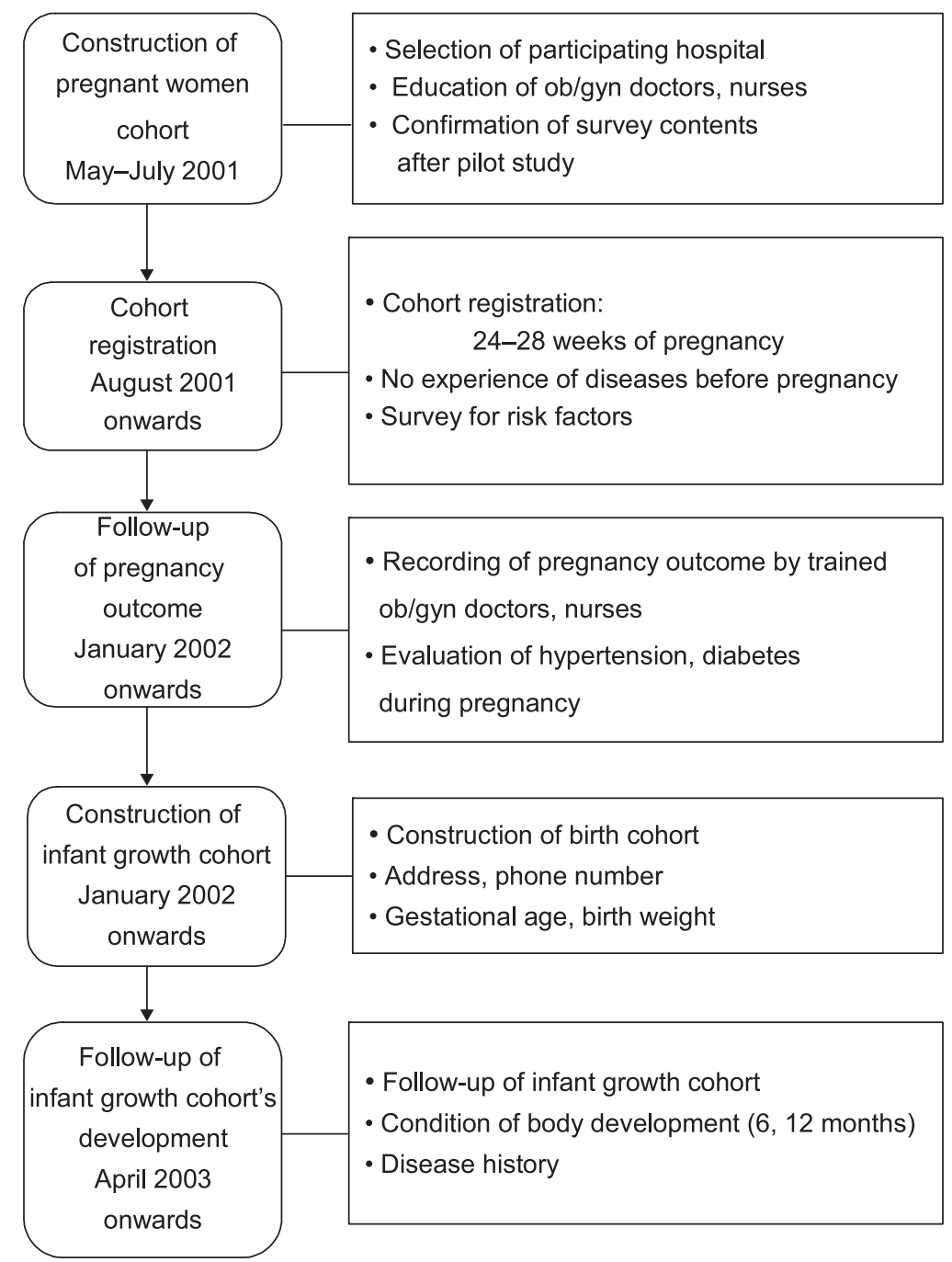

Fig. 1 Flowchart of cohort construction

Table 1 Conditions for high-performance liquid chromatography

\begin{tabular}{|c|c|c|c|}
\hline Condition & L-Ascorbic acid & $\alpha$-Tocopherol & Retinol \\
\hline Column & $\begin{array}{l}\text { Cap cell pack } 18 \\
\text { (Shimadzu) }\end{array}$ & $\begin{array}{l}\text { Cap cell pack } 18 \\
\text { (Shimadzu) }\end{array}$ & $\begin{array}{l}\text { Cap cell pack } 18 \\
\text { (Shimadzu) }\end{array}$ \\
\hline Mobile phase & $\begin{array}{l}0.01 \mathrm{M}-\mathrm{KH}_{2} \mathrm{PO}_{4} \\
(\mathrm{PIC} \mathrm{A}, 10 \mathrm{ml} / \mathrm{l})\end{array}$ & $\begin{array}{l}\text { Acetonitrile-methanol } \\
(75: 25, \mathrm{v} / \mathrm{v})\end{array}$ & $\begin{array}{l}\text { Acetonitrile-methanol } \\
(75: 25, \mathrm{v} / \mathrm{v})\end{array}$ \\
\hline Detector & UV, $254 \mathrm{~nm}$ & UV, $325 \mathrm{~nm}$ & UV, $292 \mathrm{~nm}$ \\
\hline Flow rate & $0.8 \mathrm{ml} / \mathrm{min}$ & $1 \mathrm{ml} / \mathrm{min}$ & $1 \mathrm{ml} / \mathrm{min}$ \\
\hline
\end{tabular}

UV, ultraviolet.

correlation ( $r=0.99)$ indicated that mailed measurements could be used as a substitute for outpatient measurements. The study protocol was approved by the institutional review board of Ewha Womans University.

\section{Statistical analysis}

Owing to the absence of definite deficiency criteria for maternal vitamins excluding folate and oxidative stress, they were categorised into two groups (low/high) at the 25th, 50th or 75th percentile as determined by the distribution of serum or urinary concentrations among the entire cohort. An even distribution of possible confounders such as infant sex and gestational age between the two groups could prevent outcomes from being calculated due to the presence of infinite likelihood, and hence the cut-off points for vitamins $\mathrm{A}, \mathrm{C}$ and $\mathrm{E}$, and oxidative stress were determined in a different way.

The folate concentration was categorised into a deficient group $(<6 \cdot 8 \mu \mathrm{mol} / \mathrm{l})$ and a normal group ${ }^{(39)}$. 
Vitamin A was dichotomised into high and low groups at the 25th percentile, and vitamin $\mathrm{C}$ and oxidative stress were dichotomised at the 75 th percentiles. Vitamin E was divided at the 50th percentile. The associations of maternal serum vitamin and oxidative stress levels with infant weight and height at 0,6 and 12 months were assessed by repeated-measures analysis of variance using the MIXED procedure in the Statistical Analysis Systems statistical software package version 8.0 (SAS Institute, Cary, NC, USA). Possible confounders were dealt with using three adjustments: for infant sex (Model 1); for infant sex and gestational age (Model 2); and for infant sex, gestational age, breast milk, mother's age, weight, height and job, father's weight and height, and the person who cares for the infant (Model 3).

\section{Results}

Table 2 lists the number of infants followed at birth, 6 months and 12 months, and their mean weight and height. Median value of mother's age was 31 years, and median maternal weight and height were $54 \mathrm{~kg}$ and $160 \mathrm{~cm}$ respectively. About $70 \%$ of the mothers had jobs; of the infants, $87 \%$ were cared for by the mother and $76 \%$ were breast-fed (Table 3). Most infants were exposed to second-hand smoke (83.0\%) and took nutrition supplements (66.5\%). The majority of infants were cared for at home (97.3\%), had experiences for visiting hospital (87.3\%) and did not have experiences for hospital admission (80.6\%). Nearly all fathers of infants had jobs.

Table 4 presents the infants' mean weights according to maternal vitamin and oxidative stress status while adjusting for infant sex, gestational age and the variables in Table 3 (breast milk, mother's age, weight and job, father's weight, person who cares for the infant). Infant weight at birth, 6 months and 12 months was lower in the folate-deficient group, with the differences being statistically significant $(P=0 \cdot 02)$ after adjusting for infant sex (Model 1) and for infant sex and gestational age (Model 2). The high-vitamin $C$ group exhibited elevated weight at birth, 6 months and 12 months with statistical significances, although the adjustments for infant sex (Model 1) and for infant sex and gestational age (Model 2) lowered the birth weight in this group slightly. The probability values for retinol in Models 1 and 2 were not calculated for the same reason of infinite likelihood as mentioned above.

The relationships between infant height at birth, 6 months and 12 months and maternal vitamin and oxidative stress status are indicated in Table 5. The low-folate group exhibited lower infant height at birth, 6 months and 12 months, with statistical significance $(P=0.02$ and $0 \cdot 03$ ), after adjusting both for infant sex (Model 1) and for infant sex and gestational age (Model 2). The highvitamin C group presented significantly higher infant
Table 2 Weight and height of infants at birth, 6 months and 12 months

\begin{tabular}{|c|c|c|c|c|c|c|c|c|c|}
\hline & \multicolumn{3}{|c|}{ Birth } & \multicolumn{3}{|c|}{6 months } & \multicolumn{3}{|c|}{12 months } \\
\hline & Mean & $\mathrm{SD}$ & $n$ & Mean & SD & $n$ & Mean & $S D$ & $n$ \\
\hline Wve & 3190 & 528 & 804 & 8254 & 1087 & 385 & 10008 & 1274 & 311 \\
\hline Height $(\mathrm{cm})$ & 49 & 3 & 794 & 69 & 4 & 277 & 77 & 4 & 268 \\
\hline
\end{tabular}

SD, standard deviation.

Table 3 General characteristics of subjects $(n=317)$

\begin{tabular}{lc}
\hline & Median (range) or $n(\%)$ \\
\hline Mother's age (years) & $31(20,47)$ \\
Person who cares for infant & $346(86.5)$ \\
Mother & $37(9.3)$ \\
Grandparent & $4(1.0)$ \\
Relatives & $10(2.5)$ \\
Babysitter & $1(0.3)$ \\
Kindergarten & $2(0.5)$ \\
Others & \\
Breast milk & $306(75 \cdot 6)$ \\
Yes & $99(24.4)$ \\
No & \\
Mother's job & $299(69.5)$ \\
No & $131(30.5)$ \\
Yes & $173(155,190)$ \\
Father's height $(\mathrm{cm})$ & $71(50,110)$ \\
Father's weight $(\mathrm{kg})$ & $160(142,177)$ \\
Mother's height $(\mathrm{cm})$ & $54(32,95)$ \\
Mother's weight $(\mathrm{kg})$ &
\end{tabular}

height $(P=0 \cdot 01)$ after adjusting for infant sex, gestational age, breast milk, mother's age, height and job, father's height and person who cares for the infant (Model 3). Similar to infant weight, the probability values for retinol in Models 1 and 2 were not calculated.

\section{Discussion}

To our knowledge, the current study is the first to reveal the association of maternal micronutrients and oxidative stress status with infant growth from birth to 1 year of life. Most of the previous studies investigating the associations of nutrients with infant growth have shown the impact of postpartum supplementation to mothers or infants. Stein et al. determined the impact of nutritional supplementation provided during the early childhood of women on the height of the subsequent generation ${ }^{(4)}$. Lind et al., Mwanri et al. and Schmidt et al. also reported the effects on growth of children ${ }^{(5,35,36)}$; however, they also administered nutritional supplements to the children or pregnant women participating in their studies.

The findings from this prospective cohort study of pregnant women and infants were similar to those from previous intervention studies. Similar to studies involving the administration of nutrient supplements, a high level of maternal serum nutrients was associated with increased 
Table 4 Associations of maternal vitamin status at the 24-28th week of pregnancy with mean infant weight (Model 1 is adjusted for infant sex; Model 2 is adjusted for infant sex and gestational age; Model 3 is adjusted for infant sex, gestational age, breast milk, mother's age, mother's weight, father's weight, person who cares for the infant, mother's job)

\begin{tabular}{|c|c|c|c|c|c|c|c|c|c|c|c|c|}
\hline \multirow[b]{3}{*}{ Maternal vitamin status } & \multicolumn{12}{|c|}{ Mean weight (g) } \\
\hline & \multicolumn{4}{|c|}{ Model 1} & \multicolumn{4}{|c|}{ Model 2} & \multicolumn{4}{|c|}{ Model 3} \\
\hline & Birth & 6 months & 12 months & $P$ & Birth & 6 months & 12 months & $P$ & Birth & 6 months & 12 months & $P$ \\
\hline \multicolumn{13}{|l|}{ Folate $(\mu \mathrm{mol} / \mathrm{l})$} \\
\hline Low group $(n=84)\left(<6.8^{\star}\right)$ & 2970 & 7468 & 9784 & 0.02 & 2948 & 7451 & 9791 & 0.02 & 3018 & 7888 & 9943 & 0.52 \\
\hline High group $(n=802)$ & 3051 & 8178 & 9846 & & 3028 & 8149 & 9821 & & 3050 & 8195 & 9928 & \\
\hline \multicolumn{13}{|l|}{ Vitamin A ( $\mu \mathrm{g} / \mathrm{dl})$} \\
\hline Low group $(n=221)(\leq 72 \cdot 2 t)$ & 3251 & 8173 & 10057 & & 3046 & 7955 & 9850 & & 3085 & 7896 & 9843 & 0.71 \\
\hline High group $(n=749)$ & 3274 & 8346 & 10027 & & 3065 & 8127 & 9815 & & 3011 & 8099 & 9857 & \\
\hline \multicolumn{13}{|l|}{ Vitamin $E(\mu \mathrm{g} / \mathrm{dl})$} \\
\hline Low group $(n=469)$ & 3070 & 8092 & 9823 & 0.91 & 3048 & 8063 & 9804 & 0.85 & 3020 & 8006 & 9857 & 0.12 \\
\hline High group $(n=500)(\geq 1939.8 \ddagger)$ & 3068 & 8107 & 9832 & & 3048 & 8086 & 9819 & & 3138 & 8226 & 9964 & \\
\hline \multicolumn{13}{|c|}{ Vitamin C $(\mu \mathrm{g} / \mathrm{ml})$} \\
\hline Low group $(n=687)$ & 3086 & 8057 & 9744 & 0.01 & 3060 & 8026 & 9726 & 0.004 & 3083 & 8000 & 9763 & 0.0003 \\
\hline High group $(n=243)(\geq 9.0 \S)$ & 3053 & 8344 & 10111 & & 3039 & 8329 & 10098 & & 3119 & 8557 & 10424 & \\
\hline \multicolumn{13}{|l|}{ MDA ( $\mu \mathrm{mol} / \mathrm{g}$ creatinine) } \\
\hline High group $(n=94)(\geq 2.9 \S)$ & 3184 & 7984 & 9697 & 0.08 & 3186 & 8001 & 9706 & 0.09 & 3245 & 7998 & 9755 & 0.42 \\
\hline Low group $(n=308)$ & 3280 & 8250 & 9966 & & 3275 & 8245 & 9966 & & 3221 & 8351 & 9918 & \\
\hline \multicolumn{13}{|l|}{$8-\mathrm{OHdG}(\mu \mathrm{g} / \mathrm{g}$ creatinine) } \\
\hline High group $(n=97)(\geq 0.1 \S)$ & 3246 & 8262 & 9725 & 0.60 & 3195 & 8202 & 9693 & 0.29 & 3138 & 8399 & 9649 & 0.54 \\
\hline Low group $(n=298)$ & 3258 & 8162 & 10006 & & 3270 & 8178 & 10021 & & 3293 & 8277 & 10051 & \\
\hline
\end{tabular}

MDA, malondialdehyde; 8-OHdG, 8-hydroxydeoxyguanosine.

*Folate: cut-off according to Herbert and Das ${ }^{(39)}$.

+Vitamin A (retinol): low group is lower than the 25th percentile.

$\ddagger V$ itamin $E(\alpha$-tocopherol): high group is higher than the 50th percentile.

$\S$ Vitamin C (L-ascorbic acid), MDA and 8-OHdG: high group is higher than the 75th percentile.

Table 5 Associations of maternal vitamin status at the 24-28th week of pregnancy with mean infant height (Model 1 is adjusted for infant sex; Model 2 is adjusted for infant sex and gestational age; Model 3 is adjusted for infant sex, gestational age, breast milk, mother's age, mother's height, father's height, person who cares for the infant, mother's job)

\begin{tabular}{|c|c|c|c|c|c|c|c|c|c|c|c|c|}
\hline \multirow[b]{3}{*}{ Maternal vitamin status } & \multicolumn{12}{|c|}{ Mean height $(\mathrm{cm})$} \\
\hline & \multicolumn{4}{|c|}{ Model 1} & \multicolumn{4}{|c|}{ Model 2} & \multicolumn{4}{|c|}{ Model 3} \\
\hline & Birth & 6 months & 12 months & $P$ & Birth & 6 months & 12 months & $P$ & Birth & 6 months & 12 months & $P$ \\
\hline \multicolumn{13}{|l|}{ Folate $(\mu \mathrm{mol} / \mathrm{l})$} \\
\hline Low group $(n=84)\left(<6 \cdot 8^{*}\right)$ & $48 \cdot 3$ & 67.6 & $76 \cdot 1$ & 0.02 & $48 \cdot 2$ & $67 \cdot 3$ & $76 \cdot 0$ & 0.03 & 49.8 & 70.5 & 77.5 & 0.61 \\
\hline High group $(n=802)$ & $49 \cdot 1$ & $68 \cdot 7$ & $76 \cdot 5$ & & $49 \cdot 0$ & $68 \cdot 6$ & $76 \cdot 4$ & & $50 \cdot 3$ & $70 \cdot 2$ & $78 \cdot 0$ & \\
\hline \multicolumn{13}{|l|}{ Vitamin A ( $\mu \mathrm{g} / \mathrm{dl})$} \\
\hline Low group $(n=221)(\leq 72 \cdot 2 t)$ & 49.4 & 68.6 & $77 \cdot 0$ & & $49 \cdot 0$ & $68 \cdot 3$ & $76 \cdot 7$ & & 50.9 & $70 \cdot 2$ & $78 \cdot 7$ & 0.21 \\
\hline High group $(n=749)$ & $49 \cdot 3$ & 68.9 & 76.5 & & $49 \cdot 0$ & 68.5 & $76 \cdot 2$ & & $50 \cdot 4$ & $70 \cdot 2$ & $77 \cdot 8$ & \\
\hline \multicolumn{13}{|l|}{ Vitamin E ( $\mu \mathrm{g} / \mathrm{dl})$} \\
\hline Low group $(n=469)$ & 49.1 & 68.8 & $76 \cdot 4$ & 0.30 & $49 \cdot 0$ & 68.7 & $76 \cdot 3$ & 0.32 & $50 \cdot 3$ & $70 \cdot 2$ & 77.9 & 0.33 \\
\hline High group $(n=500)(\geq 1939.8 \ddagger)$ & $49 \cdot 0$ & 68.4 & $76 \cdot 2$ & & 49.0 & 68.2 & $76 \cdot 1$ & & $50 \cdot 8$ & $70 \cdot 4$ & $78 \cdot 1$ & \\
\hline \multicolumn{13}{|c|}{ Vitamin C $(\mu \mathrm{g} / \mathrm{ml})$} \\
\hline Low group $(n=687)$ & $49 \cdot 2$ & 68.8 & $76 \cdot 4$ & 0.17 & $49 \cdot 1$ & 68.6 & $76 \cdot 2$ & 0.22 & $50 \cdot 3$ & $70 \cdot 0$ & $77 \cdot 7$ & 0.008 \\
\hline High group $(n=243)(\geq 9.0 \S)$ & 49.4 & 69.2 & $76 \cdot 9$ & & 49.2 & $69 \cdot 0$ & 76.7 & & 51.0 & $70 \cdot 8$ & 78.7 & \\
\hline \multicolumn{13}{|l|}{ MDA ( $\mu \mathrm{mol} / \mathrm{g}$ creatinine) } \\
\hline High group $(n=94)(\geq 2.9 \S)$ & 48.8 & 68.8 & 74.4 & 0.11 & 48.9 & 69.1 & 74.5 & 0.15 & 49.4 & $69 \cdot 2$ & $75 \cdot 2$ & 0.98 \\
\hline Low group $(n=308)$ & $49 \cdot 3$ & $68 \cdot 7$ & $76 \cdot 3$ & & $49 \cdot 2$ & 68.6 & $76 \cdot 3$ & & $48 \cdot 9$ & 68.7 & $76 \cdot 1$ & \\
\hline \multicolumn{13}{|l|}{$8-\mathrm{OHdG}$ ( $\mu \mathrm{g} / \mathrm{g}$ creatinine) } \\
\hline High group $(n=97)(\geq 0.1 \S)$ & 48.9 & 69.0 & $75 \cdot 6$ & 0.64 & 48.7 & 68.6 & 75.4 & 0.19 & $48 \cdot 3$ & 69.9 & 75.4 & 0.55 \\
\hline Low group $(n=298)$ & 49.2 & $68 \cdot 8$ & $76 \cdot 3$ & & $49 \cdot 3$ & 68.9 & $76 \cdot 3$ & & 49.4 & $69 \cdot 0$ & $76 \cdot 4$ & \\
\hline
\end{tabular}

MDA, malondialdehyde; 8-OHdG, 8-hydroxydeoxyguanosine.

*Folate: cut-off according to Herbert and Das ${ }^{(39)}$.

+Vitamin A (retinol): low group is lower than the 25 th percentile.

$\ddagger V i t a m i n ~ E(\alpha$-tocopherol): high group is higher than the 50th percentile.

§Vitamin C (L-ascorbic acid), MDA and 8-OHdG: high group is higher than the 75 th percentile.

infant growth. After adjusting for already-known factors such as infant sex and gestational age (in Models 1 and 2), infant weight at birth, 6 months and 12 months was significantly lower in the folate-deficient group than in the normal group. However, when adjusting for alreadyknown (infant sex and gestational age) and possible factors (breast milk, mother's age, weight and job, father's weight, person who cares for the infant) altogether (Model 3), statistical significance disappeared. This suggests that parents' characteristics play an important role in infant growth. Infant weight at birth and 6 and 12 months tended to be significantly higher in the high-vitamin C 
group with the consideration of already-known and possible factors (Model 3); however, the effects at birth were unexpectedly opposite with adjustments for infant sex and gestational age (Models 1 and 2). The fact that all three adjustments for already-known or possible factors had statistical significance points out that vitamin $\mathrm{C}$ is a strong predictor for infant growth. Similar to weight, infant height at birth and after birth was significantly lower in the folate-deficient group after adjusting for already-known factors (infant sex and gestational age, Models 1 and 2). Also, statistical significance disappeared after adjusting for already-known and possible factors (Model 3) and height at 6 months was higher in the folatedeficient group. The high-vitamin $\mathrm{C}$ group was associated with significantly higher infant heights with the consideration of both already-known and possible factors (Model 3). A high level of oxidative stress (as assessed by the levels of MDA and 8-OHdG) tended to be associated with low infant weight and height, but this relationship was not statistically significant.

There have been few studies on the direct associations of maternal serum micronutrient levels with postnatal growth. Nevertheless, these associations can be indirectly postulated from the concept of foetal programming, which explains that poor intrauterine environments (such as maternal nutrition deficiency) may induce changes in biochemical mechanisms and consequently result in reduced postnatal growth and an increased likelihood of developing disease at childhood or adulthood. There are critical periods during which structural, physiological and metabolic developments occur in utero, and retardation at these times can cause enforced adaptation to undesirable conditions that result in a wide range of permanent disabilities ${ }^{(40)}$. Our study has also found that weight and height at birth and after birth were relatively low in the low-vitamin groups. In particular, folate deficiency was strongly associated with low birth and postnatal weight and height, and sufficient vitamin $\mathrm{C}$ was significantly associated with high birth and postnatal weight and height, indicating the importance of avoiding folate deficiency and supplementing vitamin $\mathrm{C}$ among the antioxidant vitamins. Although the effects exerted by vitamin $\mathrm{A}$, vitamin $\mathrm{E}$ and oxidative stress were relatively similar to those of folate and vitamin $\mathrm{C}$, there was no statistical significance. The protective effect of vitamin $\mathrm{C}$ on weight was shown only from 6 to 12 months; therefore, it is tempting to conclude that the level of vitamin C does not influence birth weight. However, this result is not definitive in our study sample, and hence further studies are needed.

Similar to micronutrients, there are no published reports concerning the association of maternal oxidative stress with postnatal growth, while there have been a few reports on its association with foetal growth. High oxidative stress was found to be related to adverse pregnancy outcomes including low birth weight ${ }^{(34,41)}$, and presumably this inverse association would persist into postnatal growth. Although there was no statistical significance, our study revealed a potential association between high oxidative stress during pregnancy and reduced infant weight and height both at birth and after birth. Future studies should employ larger samples to clarify the importance of reducing oxidative stress in pregnant women.

Several limitations of the present study merit discussion. First, due to a low follow-up rate, differing characteristics between infants who participated in the study and those who did not could cause selection bias. This study excluded non-participants who were likely to have lower maternal nutrition, higher oxidative stress, and lower birth weight and height, which would underestimate the association (towards the null). Second, the influence of socio-economic and environmental conditions surrounding the mother and the infant on the associations between maternal nutritional factors and infant growth should have been considered in detail. Direct or indirect indicators such as the mother's education level, the family's size and socio-economic status, and household conditions have been widely studied and identified as important factors in infant nutrition and growth ${ }^{(42)}$. Our study did collect information about the mother's and father's occupations, places to care for infants, breastfeeding, weaning food, supplementation, hospital visits and admission, frequent infectious diseases and passive smoking; however, due to considerable missing data, only a few factors such as breast milk, mother's age, job, weight and height, father's weight and height and person who cares for the infant were analysed and proved as important factors. An effective technique for reducing the non-reply rate should be established, and other important factors such as lifestyle patterns and socio-economic status should be examined.

Third, although the primary method of weight and height measurement was based on a standardised and precise assessment in the hospital, not all of the data could be obtained in this way. Data on infants who did not visit the hospital at 6 or 12 months were collected by a mailed questionnaire, and this might have generated measurement errors although our Spearman correlation analysis suggested that such errors would be small. Fourth, since there was no definite deficiency or excess criteria for vitamins $\mathrm{A}, \mathrm{C}$ and $\mathrm{E}$, and oxidative stress, we dichotomised each of these variables using the 25th, 50th or 75 th percentile as the cut-off point so as to distribute possible confounders between low and high groups as unevenly as possible. Finally, this study was conducted at a single hospital, which limits its generalisability to all pregnant women.

The most noteworthy feature of this study is its prospective cohort design. In addition, the determination of maternal vitamin and oxidative stress status by means of serum and urine collected in midterm pregnancy served 
to elucidate the temporal association. Moreover, a longitudinal data set was formed so as not to exclude infants who were not followed up by the end of study, which allowed infants having at least one postnatal weight and height measurement (at 6 or 12 months) to be included in the analysis.

This study has demonstrated that a deficiency of folate causes low infant weight and height and that a high maternal status of vitamin $\mathrm{C}$ generates high infant weight and height. These results indicate the importance of preventing folate deficiency and supplementing vitamin $\mathrm{C}$ during pregnancy. In addition, parental characteristics such as age, job, weight and height and breast-feeding play important roles in infant growth during the first year of life, necessitating strategies to focus on specific groups having these characteristics. We observed and followed up a relatively small number of infants only from birth to the first year of life at one hospital setting, which makes it is somewhat difficult to produce definitive conclusions. However, the present study provides good evidence that maternal antioxidant micronutrients influence infant growth during the first year after birth.

\section{Acknowledgements}

This study was supported by a grant (no. 03-PJ1-PG1021900-0001) from the Korea Health 21 R\&D project, Ministry of Health and Social Affairs, Kwacheon, Kyunggi, South Korea. There are no competing interests. J.H. analysed and interpreted data, and drafted the article and revised it. E.A.P., Y.J.K., H.Y.L. and E.-H.H. contributed to the conception and design of study. B.-H.P. and K.A.K. were responsible for follow-up and care of the study subjects. H.P. supervised the main study.

\section{References}

1. Hininger I, Favier M, Arnaud J, Faure H, Thoulon JM, Hariveau E, Favier A \& Roussel AM (2004) Effects of a combined micronutrient supplementation on maternal biological status and newborn anthropometrics measurements: a randomized double-blind, placebo-controlled trial in apparently healthy pregnant women. Eur J Clin Nutr 58, 52-59.

2. Ramakrishnan U, Aburto N, McCabe G \& Martorell R (2004) Multimicronutrient interventions but not vitamin A or iron interventions alone improve child growth: results of 3 meta-analyses. J Nutr 134, 2592-2602.

3. Vahratian A, Siega-Riz AM, Savitz DA \& Thorp JM Jr (2004) Multivitamin use and the risk of preterm birth. Am J Epidemiol 160, 886-892.

4. Stein AD, Barnhart HX, Wang M, Hoshen MB, Ologoudou K, Ramakrishnan U, Grajeda R, Ramirez-Zea M \& Martorell $\mathrm{R}$ (2004) Comparison of linear growth patterns in the first three years of life across two generations in Guatemala. Pediatrics 113, e270-e275.

5. Lind T, Lonnerdal B, Stenlund H, Gamayanti IL, Ismail D, Seswandhana R \& Persson L-A (2004) A community-based randomized controlled trial of iron and zinc supplementa- tion in Indonesian infants: effects on growth and development. Am J Clin Nutr 80, 729-736.

6. Christian P (2003) Micronutrients and reproductive health issues: an international perspective. J Nutr 133, 1969S-1973S.

7. Conlisk AJ, Barnhart HX, Martorell R, Grajeda R \& Stein AD (2004) Maternal and child nutritional supplementation are inversely associated with fasting plasma glucose concentration in young Guatemalan adults. J Nutr 134, 890-897.

8. Zhang C, Williams MA, Sorensen TK, King IB, Kestin MM, Thompson ML, Leisentring WM, Dashow EE \& Luthy DA (2004) Maternal plasma ascorbic acid [vitamin C] and risk of gestational diabetes mellitus. Epidemiology 15, 597-604.

9. Basu S, Sengupta B \& Paladhi PK (2003) Single megadose vitamin A supplementation of Indian mothers and morbidity in breastfed young infants. Postgrad Med J 79, 397-402.

10. Cole TJ (2000) Secular trends in growth. Proc Nutr Soc 59, 317-324.

11. Franco Mdo C, Dantas APV, Akamine EH, Kawamoto EM, Fortes ZB, Scavone C, Tostes RCA, Carvalho MHC \& Nigro D (2002) Enhanced oxidative stress as a potential mechanism underlying the programming of hypertension in utero. J Cardiovasc Pharmacol 40, 501-509.

12. Fall CHD, Yajnik CS, Rao S, Davies AA, Brown N \& Farrant HJW (2003) Micronutrients and fetal growth. J Nutr 133, 1747S-1756S.

13. Yang YX, Chen XC, Liu JY, Pan LM, Yan HC \& Xu QM (2000) Effect of zinc intake on fetal and infant growth among Chinese pregnant and lactating women. Biomed Environ Sci 13, 280-286.

14. Cederberg J, Siman CM \& Eriksson UJ (2001) Combined treatment with vitamin $\mathrm{E}$ and vitamin $\mathrm{C}$ decreases oxidative stress and improves fetal outcome in experimental diabetic pregnancy. Pediatr Res 49, 755-762.

15. Merialdi M, Carroli G, Villar J, Abalos E, Gulmezoglu AM, Kulier R \& de Onis M (2003) Nutritional interventions during pregnancy for the prevention or treatment of impaired fetal growth: an overview of randomized controlled trials. J Nutr 133, 1626S-1631S.

16. Friis H, Gomo E, Nyazema N, Ndhlovu P, Krarup H, Kaestel P \& Michaelsen KF (2004) Effect of multimicronutrient supplementation on gestational length and birth size: a randomized, placebo-controlled, double-blind effectiveness trial in Zimbabwe. Am J Clin Nutr 80, 178-184.

17. Siega-Riz AM, Promislow JHE, Savitz DA, Thorp JM Jr \& McDonald T (2003) Vitamin C intake and the risk of preterm delivery. Am J Obstet Gynecol 189, 519-525.

18. Gazala E, Sarov B, Hershkovitz E, Edvardson S, Sklan D, Katz M, Friger M \& Gorodischer R (2003) Retinol concentration in maternal and cord serum: its relation to birth weight in healthy mother-infant pairs. Early Hum Dev 71, 19-28.

19. Dejmek J, Ginter E, Solansky I, Podrazilova K, Stavkova Z, Benes I \& Sram RJ (2002) Vitamin C, E and A levels in maternal and fetal blood for Czech and Gypsy ethnic groups in the Czech Republic. Int J Vitam Nutr Res $\mathbf{7 2}$, 183-190.

20. Barber DA \& Harris SR (1994) Oxygen free radicals and antioxidants: a review. Am Pharm NS34, 26-35.

21. Downie D, Antipatis C, Delday MI, Maltin CA \& Sneddon AA (2005) Moderate maternal vitamin A deficiency alters myogenic regulatory protein expression and perinatal organ growth in the rat. Am J Physiol Regul Integr Comp Physiol 288, R73-R79.

22. Katz J, West KP Jr, Khatry SK, Pradhan EK, LeClerq SC, Christian P, Wu LS, Adhikari RK, Shrestha SR \& Sommer A (2000) Maternal low-dose vitamin A or $\beta$-carotene supplementation has no effect on fetal loss and early infant mortality: a randomized cluster trial in Nepal. Am J Clin Nutr 71, 1570-1576. 
23. Suharno D, West CE, Muhilal, Karyadi D \& Hautvast JG (1993) Supplementation with vitamin A and iron for nutritional anaemia in pregnant women in West Java, Indonesia. Lancet 342, 1325-1328.

24. Rao S, Yajnik CS, Kanade A et al. (2001) Intake of micronutrient-rich foods in rural Indian mothers is associated with the size of their babies at birth: Pune Maternal Nutrition Study. J Nutr 131, 1217-1224.

25. Mathews F, Yudkin P \& Neil A (1999) Influence of maternal nutrition on outcome of pregnancy: prospective cohort study. BMJ 319, 339-343.

26. Doyle W, Crawford MA, Wynn MA \& Wynn SW (1990) The association between diet and birth dimensions. J Nutr Med 1, 9-17.

27. Chappell LC, Seed PT, Briley AL et al. (1999) Effect of antioxidants on the occurrence of pre-eclampsia in women at increased risk: a randomized controlled trial. Lancet $\mathbf{3 5 4}$, 810-816.

28. Oakley GP Jr (2003) Folate deficiency is an imminent health hazard' causing a worldwide birth defects epidemic. Birth Defects Res A Clin Mol Teratol 67, 903-904.

29. Wagner C (1995) Biochemical role of folate in cellular metabolism. In Folate in Health and Disease, pp. 23-42 [LB Bailey, editor]. New York: Marcel Dekker.

30. Ramakrishnan U, Manjrekar R, Rivera J, Gonzales-Cossio T \& Martorell R (1999) Micronutrients and pregnancy outcome: a review of the literature. Nutr Res 19, 103-159.

31. Scholl TO \& Johnson WG (2000) Folic acid: influence on the outcome of pregnancy. Am J Clin Nutr $\mathbf{7 1}$, 1295S-1303S.

32. De Weerd S, Steegers-Theunissen RP, de Boo TM, Thomas CM \& Steegers EA (2003) Maternal periconceptional biochemical and hematological parameters, vitamin profiles and pregnancy outcome. Eur J Clin Nutr $\mathbf{5 7}$, 1128-1134.
33. Bowen RS, Moodley J, Dutton MF \& Theron AJ (2001) Oxidative stress in pre-eclampsia. Acta Obstet Gynecol Scand 80, 719-725.

34. Scholl TO \& Stein TP (2001) Oxidant damage to DNA and pregnancy outcome. J Matern Fetal Med 10, 182-185.

35. Mwanri L, Worsley A, Ryan P \& Masika J (2000) Supplemental vitamin A improves anemia and growth in anemic school children in Tanzania. J Nutr 130, 2691-2696.

36. Schmidt MK, Muslimatun S, Schultink W, West CE \& Hautvast JGAJ (2002) Randomized double-blind trial of the effect of vitamin A supplementation of Indonesian pregnant women on morbidity and growth of their infants during the first year of life. Eur J Clin Nutr 56, 338-346.

37. Kutnink MA, Hawkes WC, Schaus EE \& Amaye ST (1987) An internal standard method for the unattended highperformance lipid chromatographic analysis of ascorbic acid in blood components. Anal Biochem 166, 424.

38. Bieri MA, Tolliver TJ \& Catignani GL (1979) Simultaneous determination of $\alpha$-tocopherol and retinol in plasma and red cells by high pressure lipid chromatography. Am J Clin Nutr 32, 2143-2149.

39. Herbert V \& Das KC (1994) Folic acid and vitamin B-12. In Modern Nutrition in Health and Disease, pp. 402-425 [ME Shils, JA Olson \& M Shike, editors]. Philadelphia, PA: Lea and Febiger.

40. Cianfarani S (2003) Foetal origins of adult diseases: just a matter of stem cell number? Med Hypotheses 61, 401-404.

41. Wang Y \& Walsh SW (2001) Increased superoxide generation is associated with decreased superoxide dismutase activity and mRNA expression in placental trophoblast cells in pre-eclampsia. Placenta 22, 206-212.

42. Lima MdeC, Motta ME, Santos EC \& Pontes da Silva GA (2004) Determinants of impaired growth among hospitalized children: a case-control study. Sao Paulo Med J 122, 117-123. 